\title{
Politics matters: a response to recent commentaries
}

\author{
Ruairí Brugha $^{1, *}$, Carlos Bruen $^{2}$
}

*Correspondence to: Ruairí Brugha, Email: rbrugha@rcsi.ie Copyright: () 2014 by Kerman University of Medical Sciences Citation: Brugha R, Bruen C. Politics matters: a response to recent commentaries. Int J Health Policy Manag 2014; 3: 157-158. doi: 10.15171/ijhpm.2014.80 Received: 19 August 2014, Accepted: 27 August 2014, ePublished: 27 August 2014

\section{$\mathrm{M}$} cCoy and Singh rightly comment on how extraordinary it is to need to spell out the political nature, actions and motivations underlying global health policy (1), which articulates where they (and we) are coming from. Yet without such commentators, it would be easy for the global health community today to forget how political and macro-economic decisions in the 1980s and 90s gave oxygen to the social determinants that undermined the health of populations, especially in low-income countries. These fuelled the diseases that are the focus of today's global health partnerships; and some of the same organisations played leading roles in setting the global health agenda then, as today.

The editorial (2) and commentaries $(1,3,4)$ raise questions about the scope for a broader engagement around the politics of global health, throwing light on the need for analysis, reflection and dialogue. For instance, among those engaged in how best to 'do disease control' are communities that have countervailing ideologies. There are those, referred to by Harmer, McCoy and Singh, who see global health and development mainly as a technocratic challenge. They include not only those who promote selective or vertical disease control, but also those (including us) who bring competing ideas and evidence for prioritising health systems' strengthening. For the latter, 'human resources for health' can take on the sacrosanct symbolism that new vaccines or access to medicines have for the former.

The competition of ideas and evidence between different communities, which has acted as an undercurrent that has shaped GAVI Alliance and Global Fund policies since their foundation, has roots that stretch back further than the debates that followed from the 1978 Alma Ata Declaration, or even the competition between those promoting disease eradication versus social and economic improvement in the 1950s (5). David Bradley (6) illustrates how geopolitical interests underlay the contested nature of disease control in the early decades of the $20^{\text {th }}$ century. In charting the history of malaria control, he noted how "the battle over eradication was fought with vigour and much bitterness", where contestation between control approaches cloaked the interests of the actors and reflected "competition for resources... contrasting paradigms or even pieces of academic turf... (and) the natural tendency of international organizations to dogmatism". By seeking to reveal the obvious-through spelling out the political and ideological positions that underpin alternative disease control approaches-we continue a tradition set by others (7). This is to encourage those who make their lives in global health to reflect more critically and with some historical awareness on their own assumptions; and to seek to better understand the positions and actions of other global health actors. A lack of awareness and acknowledgement of how much energy goes into the defence of competing ideas, which is itself a political action, can undermine the collective efforts of communities that share a common aim. However, ideas also reflect underlying competing ideologies and can represent stark choices-whether framed in terms of global inequities, Schedler's simplistic imagery or Mosse's 'mobilizing metaphors' (1)-in that they determine how global health challenges are conceptualised, funded and tackled.

McCoy's and Singh's analysis goes beyond the narrower understanding of global health that framed our editorial. It points to a very different type of community, who cannot be accused of lacking political awareness, who have used anti-political rhetoric for political and strategic reasons. The model of global development in the 1980s and 90s, which entrenched and exacerbated the social determinants and inequities in health within and across countries, continues to exist. It is now deeply entwined with global commercial interests, such as those which undermine population health and entrench inequities through promoting obesogenic food and tobacco consumption, adding to the potent mix.

Those who seek to 'do disease control'-be it as an expression of corporate responsibility in a public-private partnership, as a philanthropic endeavour, or those across a range of development agencies, academia and NGOs who have chosen global health as a career path-all have a responsibility to recognise the political and economic inequities that frame their fields of action. Acknowledging the politics is not an excuse to stand above the political fray. However, academics do have a role to play in charting a common ground for dialogue, as well as pointing out where anti-political rhetoric has been used for political and strategic reasons. For those who acknowledge the political dimensions of global health and development, the field is ripe for political analysis and for generating a better understanding of why politics matters.

Ethical issues

Not applicable.

Competing interests

Authors declare that they have no competing interests. 
Authors' contributions

$\mathrm{RB}$ and $\mathrm{CB}$ conceptualised and designed the document; RB drafted and edited document; RB and CB revised and edited the document; RB and CB agreed final draft.

\section{References}

1. McCoy D, Singh G. A spanner in the works? anti-politics in global health policy; Comment on "A ghost in the machine? politics in global health policy”. Int J Health Policy Manag 2014; 3: 151-3. doi: 10.15171/ijhpm.2014.77

2. Bruen C, Brugha R. A Ghost in the Machine? Politics in Global Health Policy. Int J Health Policy Manag 2014, 3: 1-4. doi: 10.15171/ijhpm.2014.59

3. Kevany S. Global health diplomacy: a 'Deus ex Machina' for international development and relations; Comment on "A ghost in the machine? politics in global health policy". Int $\mathrm{J}$ Health Policy Manag 2014, 3: 111-2. doi: 10.15171/ijhpm.2014.67

4. Harmer A. Democracy - the real 'ghost' in the machine of global health policy; Comment on "A ghost in the machine? politics in global health policy". Int J Health Policy Manag 2014; 3: 149_ 150. doi: 10.15171/ijhpm.2014.75

5. Farley J. To Cast Out Disease: A History of the International Health Division of Rockefeller Foundation (1913-1951). Oxford: Oxford University Press; 2003.

6. Bradley DJ. The particular and the general. Issues of specificity and verticality in the history of malaria control. Parassitologia 1998; 40: 5-10.

7. Walt G. Health Policy: An introduction to process and power. Johannesburg and London: Wits University Press and ZED Books; 1994. 